\title{
Do tree-species richness, stand structure and ecological factors affect the photosynthetic efficiency in European forests?
}

\author{
F. Bussotti and M. Pollastrini \\ University of Florence, Department of Agrifood Production and Environmental Science (DISPAA), \\ Piazzale delle Cascine 28, 50144 Florence, Italy
}

Correspondence to: F. Bussotti (filippo.bussotti@unifi.it) and M. Pollastrini (martina.pollastrini@unifi.it)

Received: 16 September 2015 - Revised: 22 October 2015 - Accepted: 26 October 2015 - Published: 13 November 2015

Forest trees live in a multi-factor environment that includes the abiotic characteristics of the site (climate, soil, bedrock) and the structural features of the forest stand (tree age, density, leaf area index, tree species composition). The analysis of the functional traits (morphological, chemical and physiological, see Bussotti and Pollastrini, 2015) at leaf and tree level allows for the assessment and evaluation of the responses of trees to changing environmental factors. Among the physiological traits, the analysis of the chlorophyll fluorescence (ChlF, namely the prompt fluorescence and OJIP test, Strasser et al., 2004) is an effective tool to assess in vivo plant stress in experimental studies. The application of ChlF on mature trees in large-scale studies is more problematic due to the difficulty to reach tree canopies in forests, although some experiences were carried out at the local scale (Koprowski et al., 2015). ChlF measurements and analyses with the OJIP test allow to collect a great amount of data on the light-use efficiency in photosynthetic processes (one measurement takes $1 \mathrm{~s}$ and it is possible to make many replications in a short time). Furthermore, the ChlF induction curve, evaluated by means of OJIP test, produces multi-parametric information on the potential photosynthetic efficiency.

A large-scale application of OJIP test in forests was carried out within the 7FP project FunDivEUROPE (Functional Significance of Forest Biodiversity in Europe), aimed at assessing the functional significance of forest diversity in $\mathrm{Eu}-$ rope (Baeten et al., 2013). The effects of tree diversity on the photosynthetic efficiency of tree species were assessed in the exploratory platform of FunDivEUROPE, that includes six European mature forests (monocultures and mixed up to five species) distributed along a latitudinal gradient (from Mediterranean to boreal). FunDivEUROPE also in- cluded an experimental platform, consisting of mixed forest stands planted ad hoc with different levels of tree-species richness. These experimental stands were installed during the implementation of the previous projects when trees were still young. The aims of this contribution are (i) to explore the variability of ChlF parameters along European ecological gradients and (ii) to compare the responses to diversity in young mixed plantations and in mature forests. For the latter purpose, we selected the sites with Picea abies(L.) Karst. (spruce), the most widespread tree species in experimental and exploratory sites.

The leaf sampling was carried out in the summers between 2011 and 2013, by means of tree climbers, extension loppers and gun shooters, according to the height of the trees, the stand structure, and the operational conditions in each region. After sampling, branchlets were put in hermetic plastic bags and humidified to avoid leaf dehydration. ChlF measurements were done with a Handy PEA fluorimeter (Plant Efficiency Analyser, Hansatech Instruments Ltd., Petney, Norfolk, UK) after $4-5 \mathrm{~h}$ of sample dark adaptation on 16 leaves per plant (in conifers only current year needled were measured). A long dark adaptation period was necessary to reduce the effects of photoinhibition.

Fluorescence rise OJIP curves were induced by $1 \mathrm{~s}$ pulses of red light $\left(650 \mathrm{~nm}, 3500 \mu \mathrm{mol} \mathrm{m}^{-2} \mathrm{~s}^{-1}\right)$. Plotted on a logarithmic time scale, the fluorescence transients show a polyphasic shape. The initial fluorescence level, indicated with " $O$ ", is the beginning of the fluorescence emission. Following the " $K$ " time step ( $300 \mu \mathrm{s})$, the " $J$ " ( $\sim 2$ to $3 \mathrm{~ms})$ and "I" time steps ( $\sim 30 \mathrm{~ms})$ reflect the intermediate level of the fluorescence emission. The maximum level of the fluorescence emission is " $P$ " (the peak, at $500-800 \mathrm{~ms}-1 \mathrm{~s}$ ). The 
Table 1. Pearson correlation ( $p$ values) of the OJIP-test parameters of spruce in relation to tree diversity in exploratory and experimental sites of the FunDivEUROPE project. Arrows indicate the direction of the correlation ( $\downarrow=$ negative; $\uparrow=$ positive). Significances of correlations are presented for $p<0.05$.

\begin{tabular}{lrrrrr} 
& $F_{\mathrm{V}} / F_{\mathrm{M}}$ & $\Psi_{\mathrm{Eo}}$ & $\Psi_{\mathrm{Ro}}$ & $\mathrm{PI}_{\mathrm{ABS}}$ & $\mathrm{PI}_{\mathrm{TOT}}$ \\
\hline Exploratory sites & & & & & \\
\hline $\begin{array}{l}\text { North Karelia (Finland) } \\
\text { Bialowieza (Poland) }\end{array}$ & $<0.05(\downarrow)$ & $<0.05(\downarrow)$ & $<0.01(\downarrow)$ & $<0.01(\downarrow)$ \\
Hainich (Germany) & & & & \\
Râşca (Romania) & $<0.05(\uparrow)$ & & $<0.001(\uparrow)$ & \\
Experimental sites & & & & \\
Satakunta (Finland) & $<0.001(\uparrow)$ & $<0.001(\uparrow)$ & & $<0.001(\uparrow)$ & $<0.05(\uparrow)$ \\
Kaltenborn (Germany) & $<0.01(\downarrow)$ & & $<0.05(\downarrow)$ & \\
\hline
\end{tabular}
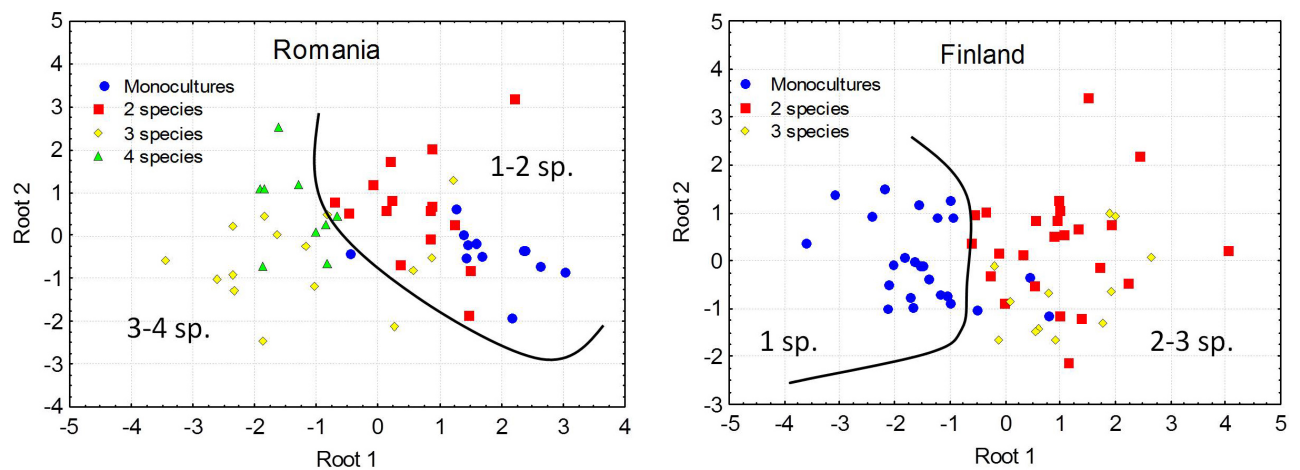

Figure 1. Discriminant analysis applied on the exploratory sites of Romania and Finland. Homogeneous groups are defined in based on the species richness. We observe that few species plots are roughly distinct from the majority of species plots.

fluorescence OJIP transients were analyzed with the OJIP test (Strasser et al., 2004; Tsimilli-Michael and Strasser, 2008). For this study, the following ChlF parameters were considered: (i) the capacity of the photosystem II (PSII) reaction centres to trap an absorbed photon $\left(F_{\mathrm{V}} / F_{\mathrm{M}}\right.$, quantum yield efficiency); (ii) the density of the reaction centres per unit of absorbing pigment (RC/ABS); (iii) the probability of a trapped electron to move into the electron transport chain $\left(\Psi_{\mathrm{Eo}}\right.$, ); (iv) the efficiency of a trapped electron to move into the electron transport chain, from $\mathrm{QA}^{-}$to the PSI end electron acceptors $\left(\Psi_{\mathrm{Ro}}\right)$; (v) the performance indices for energy conservation of photons absorbed by PSII, through the electron transport chain $\left(\mathrm{PI}_{\mathrm{ABS}}\right)$ and (vi) for energy conservation until the reduction of the final acceptors beyond the PSI (PI $\mathrm{TOT}_{\text {). }}$.

The general pattern of the ChlF parameters, evidenced by means of principal component analysis (PCA), displays that the above parameters are grouped in two clusters: the main cluster (factor $1,35.3 \%$ variability explained) included $F_{\mathrm{V}} / F_{\mathrm{M}}, \Psi_{\mathrm{Eo}}, \mathrm{RC} / \mathrm{ABS}$ and $\mathrm{PI}_{\mathrm{ABS}}$ and was directly related to the latitude, LAI (leaf area index) and basal area. The second cluster (factor 2, $17.8 \%$ variability explained), including $\Psi_{\mathrm{Ro}}$ and $\mathrm{PI}_{\mathrm{TOT}}$, was directly related to solar radiation, temperature, drought condition, and inversely to latitude.
Different responses of spruce in relation to tree-species richness were assessed among the sites of the experimental and exploratory platforms (Table 1).

In the experimental platform (Satakunta, Finland and Kaltenborn, Germany) tree diversity induced changes in the quantum yield capacity $\left(F_{\mathrm{V}} / F_{\mathrm{M}}\right)$, with an opposite patterns between the two sites. Differences between the two sites were connected to the different levels of development of the stand; Satakunta's spruces grow under the protection of the tallest birches (Betula pendula Roth.) in mixed plots, as to avoid photoinhibition (Pollastrini et al., 2014). Among the exploratory sites, no effects of diversity on ChlF parameters were detected at Hainich (Germany) and Bialowieza (Poland), whereas opposite trends were observed at Râşca (Romania) and North Karelia (Finland). In the first site, the photosynthetic efficiency was enhanced by tree diversity, whereas in the second it was depressed. Such patterns were connected to the behaviour of $\Psi_{\text {Eo }}$ (capacity to reduce primary acceptors of electrons). That may indicate different strategies in the competition for soil resources. In particular, the detrimental effect of diversity in Finland may be attributed to the competition for limited resources in extreme ecological conditions. 
A multivariate statistic (discriminant analysis) based on ChlF parameters was applied to evaluate the consistency of the groups attributed (site and species richness). The results show that the same species at different sites (exploratory and experimental) forms distinct clusters, suggesting that the ChlF properties were influenced by the ecology of the site and by the degree of development of the stand. As far as the diversity is concerned, the capacity of ChlF to identify different levels of tree-species richness is less evident. However, in Romania and Finland, few species plots were roughly distinct from the majority of species plots (Fig. 1).

In conclusion, the most relevant findings can be summarized as follows. (1) Tree diversity affects the tree photosynthetic efficiency. The effects, detected with ChlF analysis are variable depending on the relative position of the tree crowns in the canopy layer as well as the competition at the aboveground (competition for light) and below-ground (competition for water and nutrients) levels. (2) Data on young experimental plantation and mature forest cannot be compared because of the different degree of evolution of the forest stand and soil. (3) The multivariate statistical analyses of ChlF parameters allow for the identification of trees of the same species growing in different ecological condition and (although to a lesser extent) the effects of tree-species richness.

Acknowledgements. The research leading to these results received funding from the European Union Seventh Framework Programme (FP7/2007-2013) under grant 265171. We thank all the FunDivEUROPE community, especially the "leaf team", the site managers, technicians and tree climbers.

Edited by: D. Montesinos

Reviewed by: H. Kalaji and V. Goltsev

\section{References}

Baeten, L., Verheyen, K., Wirth, C., Bruelheide, H., Bussotti, F., Finér, L., Jaroszewicz, B., Selvi, F., Valladares, F., Allan, E., Ampoorter, E., Auge, H., Avăcăriei, D., Barbaro, B., Bărnoaiea ,I., Bastias, C. C., Bauhus, J., Beinhoff, C., Benavides, R., Benneter, A., Berger, S,, Berthold,F., Boberg, J., Bonal, D., Brüggemann, W., Carnol, M., Castagneyrol, B., Charbonnier, Y., Chécko, E., Coomes, D., Coppi, A., Dalmaris, E., Dănilă, G., Dawud, S. M., de Vries, W., De Wandeler, H., Deconchat, M., Domisch, T., Duduman, G., Fischer, M., Fotelli, M., Gessler, A., Gimeno, T. E., Granier, A., Grossiord, C., Guyot, V., Hantsch, L., Hättenschwiler, S., Hector, A., Hermy, M., Holland, V., Jactel, H., Joly, F.-X., Jucker, T., Kolb, S., Koricheva, J., Lexer, M. J., Liebergesell, M., Milligan, H., Müller, M., Muys, B., Nguyen, D., Nichiforel, L., Pollastrini, M., Proulx, R., Rabasa, S., Radoglou, K., Ratcliff, S., Raulund-Rasmussen, K., Seiferling, I., Stenlid, J., Vesterdal, L., von Wilpert, K., Zavala, M. A., Zielinski, D., and Scherer-Lorenzen, M.: A novel comparative research platform designed to determine the functional significance of tree species diversity in European forests, Persp. Pl. Ecol. Evolut. Syst., 15, 281-291, 2013.
Bussotti, F. and Pollastrini, M.: Evaluation of leaf features in forest trees: methods, techniques, obtainable information and limits, Ecol. Ind., 52, 219-230, 2015.

Koprowski, M., Robertson, I., Wils, T. H. G., and Kalaji, H. M.: The application of potato starch effluent causes a reduction in the photosynthetic efficiency and growth of Scots pine (Pinus sylvestris L.), Trees - Struct. and Funct., 29, 1471-1481, 2015.

Pollastrini, M., Holland, V., Brüggemann, W., Koricheva, J., Jussila, I., Scherer-Lorenzen, M., Berger, S., and Bussotti, F.: Interactions and competition processes among tree species in young experimental mixed forests, assessed with chlorophyll fluorescence and leaf morphology, Plant Biol., 16, 323-331, 2014.

Strasser, R. J., Tsimilli-Michael, M., and Srivastava, A.: Analysis of the fluorescence transient, in: Chlorophyll fluorescence: a Signature of Photosynthesis, edited by: Papageorgiou, G. C. and Govindjee, Advances in Photosynthesis and Respiration Series, Springer Dordrecht, the Netherlands, 321-362, 2004.

Tsimilli-Michael, M. and Strasser, R. J.: In vivo assessment of stress impact on plants' vitality: applications in detecting and evaluating the beneficial role of Mycorrhization on host plants, in: Mycorrhiza: State of the Art, Genetics and Molecular Biology, EcoFunction, Biotechnology, Eco-Physiology, Structure and Systematics, edited by: Varma, A., vol. 3, Springer Dordrecht, the Netherlands, 679-703, 2008. 